\title{
Exploring spatial nonstationary environmental effects on Yellow Perch distribution in Lake Erie
}

\author{
Changdong Liu ${ }^{1}$, Junchao Liu ${ }^{1}$, Yan Jiao ${ }^{2}$, Yanli Tang ${ }^{\text {Corresp., } 1}{ }^{\text {, Kevin B. Reid }}{ }^{3}$ \\ 1 Department of Fisheries, Ocean University of China, Qingdao, Shandong, China \\ Department of Fish and Wildlife Conservation, Virginia Polytechnic Institute \& State University, Blacksburg, Virginia, USA \\ 3 Department of Integrative Biology, University of Guelph, Guelph, Canada \\ Corresponding Author: Yanli Tang \\ Email address: changdong_ouc@163.com
}

Background: Global regression models under an implicit assumption of spatial stationarity were commonly applied to estimate the environmental effects on aquatic species distribution. However, the relationships between species distribution and environmental variables may change among spatial locations, especially at large spatial scales with complicated habitat. Local regression models are appropriate supplementary tools to explore species-environment relationships at finer scales.

Method: We applied geographically weighted regression (GWR) models on Yellow Perch in Lake Erie to estimate spatially-varying environmental effects on the presence probabilities of this species. Outputs from GWR were compared with those from generalized additive models (GAMs) in exploring the Yellow Perch distribution. Local regression coefficients from the GWR were mapped to visualize spatially-varying species-environment relationships. $K$-means cluster analyses based on the $t$-values of GWR local regression coefficients were used to characterize the distinct zones of ecological relationships.

Results: GWR resulted in a significant improvement over the GAM in goodness-of-fit and accuracy of model prediction. Results from the GWR revealed the magnitude and direction of environmental effects on Yellow Perch distribution changed among spatial locations. Consistent species-environment relationships were found in the west and east basins for adults. The different kinds of speciesenvironment relationships found in the central management unit implied the variation of relationships at a scale finer than the management unit.

Conclusions: This study draws attention to the importance of accounting for spatial nonstationarity in exploring species-environment relationships. The GWR results can provide support for identification of unique stocks and potential refinement of the current jurisdictional management unit (MU) structure toward more ecologically relevant MUs for the sustainable management of Yellow Perch in Lake Erie. 


\section{Exploring spatial nonstationary environmental effects on}

\section{Yellow Perch distribution in Lake Erie}

3

4

5

6

7

8 9
Changdong Liu ${ }^{1}$, Junchao Liu ${ }^{1}$, Yan Jiao ${ }^{2}$, Yanli Tang ${ }^{1}$, Kevin B. Reid ${ }^{3}$

${ }^{1}$ Department of Fisheries, Ocean University of China, Qingdao, Shandong, China

${ }^{2}$ Department of Fish and Wildlife Conservation, Virginia Polytechnic Institute \& State University, Blacksburg, VA, USA

${ }^{3}$ Department of Integrative Biology, University of Guelph, Guelph, Canada

Corresponding Author:

Yanli Tang ${ }^{1}$

No.5 Yushan Road, Qingdao, Shandong, 266003, China

Email address: tangyanli@ouc.edu.cn 
17 Abstract

Background: Global regression models under an implicit assumption of spatial stationarity were commonly applied to estimate the environmental effects on aquatic species distribution. However, the relationships between species distribution and environmental variables may change among spatial locations, especially at large spatial scales with complicated habitat. Local regression models are appropriate supplementary tools to explore species-environment relationships at finer scales.

Method: We applied geographically weighted regression (GWR) models on Yellow Perch in Lake Erie to estimate spatially-varying environmental effects on the presence probabilities of this species. Outputs from GWR were compared with those from generalized additive models (GAMs) in exploring the Yellow Perch distribution. Local regression coefficients from the GWR were mapped to visualize spatially-varying species-environment relationships. $K$-means cluster analyses based on the $t$-values of GWR local regression coefficients were used to characterize the distinct zones of ecological relationships.

Results: GWR resulted in a significant improvement over the GAM in goodness-of-fit and accuracy of model prediction. Results from the GWR revealed the magnitude and direction of environmental effects on Yellow Perch distribution changed among spatial locations. Consistent species-environment relationships were found in the west and east basins for adults. The different kinds of species-environment relationships found in the central management unit implied the variation of relationships at a scale finer than the management unit.

Conclusions: This study draws attention to the importance of accounting for spatial nonstationarity in exploring species-environment relationships. The GWR results can provide support for identification of unique stocks and potential refinement of the current jurisdictional management unit (MU) structure toward more ecologically relevant MUs for the sustainable management of Yellow Perch in Lake Erie.

\section{Introduction}

Estimating the key relationships between species distribution and environmental variables is essential for natural resource conservation and ecosystem-based fishery management ( $\mathrm{Gr}$ üss et al., 2017). A large number of published papers reported that environmental variations caused changes in species abundance and distribution (e.g. Tseng et al., 2013; Barbeaux \& Holloweb, 2017; Liu et al., 2017; Muška et al., 2018). Many biotic and abiotic factors, as well as the interactions among them, drive the species distribution at variable spatial-temporal scales. It is challenging to disentangle environmental effects on species distribution because of the spatial dynamic response of species to environmental variation. Exploring environmental effects on species distribution at a single large spatial scale may mask the intrinsic relationships between them at finer scales. Accounting for spatial nonstationarity can improve our understanding of the interactive process between species distribution and environmental variables at various spatial 
scales (Windle et al., 2010; Windle et al., 2012; Sadorus et al., 2014; Liu et al., 2017; Li et al., 2018; Bi et al. 2019).

Global regression models are the predominant methods used to estimate environmental effects on species distribution presently. Generalized additive models (GAMs) are also popular and are considered superior to generalized linear models (GLMs) for estimating the nonlinear relationships between species distribution and environmental variables (e.g. Canepa et al., 2017; Grieve et al., 2017; Hemami et al., 2018). These models estimate one average regression parameter, independent of locations and directions, for each explanatory variable over the entire study area. Due to the complexity of aquatic ecosystems and the dynamic interaction between biology and environment, the assumption of spatial stationary relationships between biological and environmental factors may be violated, especially at large spatial scales. Thus, local regression models can be effectively complement global models in inferring species-environment relationships at finer scales (Fotheringham et al., 2002).

The spatial expansion model (SEM) is one of the early methods used to estimate spatiallyvarying ecological relationships (Fotheringham et al., 1997; Li et al. 2016a). In SEM, each regression parameter itself is a function of spatial location and the form of the function (e.g. linear, polynomial) is determined by prior knowledge. The results from SEM are sensitive to the spatial expansion function and are hard to explain due to use of the complex function (e.g. highorder polynomial). The geographically weight regression (GWR) model is a natural evolution of SEM. In GWR, a local regression model is fitted at each sample location using neighborhood observations. The weights of neighborhood observations on regression points are defined according to spatial dependence and the weighted least square (WLS) method can be used to fit a local regression model. The main advantage of GWR is that it yields a set of parameter estimates at each sample location and the regression coefficients for each environmental variable can be mapped over the study area to visualize spatially-varying ecological relationships (Fotheringham et al., 2002).

Lake Erie is the smallest in volume but biologically most productive of the Laurentian Great Lakes (Hartman, 1972). The lake is separated into west, central and east basins as the significant environmental differences among them. Yellow Perch (Perca flavescens) is one of the most important commercial and recreational species in Lake Erie and plays an important role in regional economic development (YPTG, 2015). Based on morphology, Lake Erie is comprised of three main basins. Management of this species is based on management units (MUs), which correspond coarsely to the three basins, with the larger central basin separated into two MUs (YPTG, 2015). The current division of four MUs for Yellow Perch fisheries management is based on limnology, geography and tagging studies but also on historical statistical harvest district boundaries (YPTG 1983; Cowan and Paine 1997). The definitions of MU boundaries are convenient for landing and reports of harvesting, and are jurisdictional in nature, with uncertain ecological relevance. Genetic and morphological studies have provided evidence of differences in Yellow Perch stocks among MUs (Kocovsky and Knight, 2012; Sepulveda-Villet and Stepien, 2011), however, recent tagging studies indicated large scale fish movement among MUs especially among MUs 2 and 3 (Peterson, 2014; Personal communication with Andy Cook from 
95

96

97

98

99

100

101

102

103

104

105

106

107

108

109

110

111

112

113

114

115

116

117

118

119

120

121

122

123

124

125

126

127

128

129

130

131

132

Ontario Ministry of Natural Resources). We expect the discrete stocks will, to some degree, present differential responses to environment changes. Hence exploring spatially-varying species-environment relationships can provide support for identification of distinct stocks and refinement of MUs.

Water temperature, water depth, water transparency and dissolved oxygen (DO) are the key habitat variables to affect Yellow Perch distribution and several published studies had applied global regression models to estimate the environmental effects on Yellow Perch distribution (Power \& Heuvel, 1999; Arend et al., 2011; Bacheler et al., 2011; Yu et al., 2011; Manning et al., 2013; Liu et al., 2018). In this study, we questioned the spatial-stationarity assumption and explored spatially-varying species-environment relationships of Yellow Perch in Lake Erie using the GWR method. The performance of GWR was compared with that of GAM to test whether GWR outperforms GAM. We mapped the coefficient estimates of GWR to visualize ecological relationships and characterized the special zones of these relationships. Our objective was to discover species-environment relationships at finer scales to support possible refinement of the MUs toward improved management based on discrete Yellow Perch stocks.

\section{Materials \& Methods}

\section{Study area and data sources}

The partnership index survey (PIS) was conducted using the standard gillnets by the Ontario Ministry of Natural Resources and Forestry and the Ontario Commercial Fisheries' Association in the Canadian waters of Lake Erie in annual late summer and early fall. A depth-based stratified random sampling design was used and the number of sample sites was determined according to the surface area of each depth stratum (see Berger et al., 2012; Pandit et al., 2013; Liu et al., 2018). The survey gillnet gangs composed of 14 different mesh sizes were set on the bottom and suspended (canned) in the water column with a mean soak time of $20 \mathrm{~h}$.

PIS measured the catch in weight and in number of Yellow Perch by age (age 0 , age 1, age 2, etc.) at each sample. The ages of fish caught were estimated, initially by scales, and later by otoliths (YPTG, 2015). The environmental effects on Yellow Perch distribution depend on life stages (Liu et al., 2018). Accordingly, we divided the catches into juveniles (age $<2$ ) and adults with (age $\geqslant 2$ ) because the age of recruitment to the Yellow Perch fishery was defined as age-2 fish. The catches for juveniles were simplified as $0 / 1$ indicating absence/presence of fish at each sample. The corresponding operation was done for adults. Water temperature $\left({ }^{\circ} \mathrm{C}\right)$, water transparency $(\mathrm{m})$ and dissolved oxygen concentration $(\mathrm{mg} / \mathrm{L})$ were measured at the depth of gillnet (the depth from the water surface to the bottom of gillnet). Water transparency was estimated based on the visual distance of Secchi disk. To calculate distance, sample location coordinates denoted as longitude and latitude were converted to plane coordinates by the North American Datum 1983 Universal Transverse Mercator 17N projection. As benthivorous fish, only $6 \%$ in weight of the total Yellow Perch catch was found in the canned gillnets, and therefore we analyzed data from bottom gillnets only. The survey data from 1989 to 2015 included a total 
133

134

135

136

137

138

139

140

141

142

143

144

145

146

147

148

149

150

151

152

153

154

155

156

157

158

159

160

161

162

163

164

165

166

of 2502 samples that were analyzed in this study after removing the missing/erroneous values (108) in the catch or environmental data (Fig. 1).

\section{Model development}

The fish catch data for each sample were simplified as $0 / 1$ to indicate absence/presence of

Yellow Perch. We built models to estimate the relationships between the presence probability of

Yellow Perch and environmental factors. Water temperature, water depth, water transparency and dissolved oxygen concentration were used as explanatory variables in the model analysis because they were surveyed contemporaneously with the fish data and were proved to be the key habitat variables to Yellow Perch distribution (Liu et al., 2018). A preliminary variance inflation factor (VIF) analysis was conducted to test for multicollinearity of explanatory variables. The environmental factors with VIFs greater than 3 were excluded in the next model analysis

(Sagarese et al., 2014). As all the VIFs were less than 2, the four environmental variables were included in the following model analysis.

We first applied GAMs to estimate the environmental effects on the presence probabilities of juveniles and adults. GAMs extend the generalized linear models (GLMs) by replacing the linear predictors with spline functions to estimate the nonlinear relationships between response and explanatory variables (Wood, 2006). In the study, GAMs are denoted as:

$$
\ln \left(\frac{y^{*}}{1-y^{*}}\right)=\beta_{0}+\sum_{k=1}^{4} S_{k}\left(x_{k}\right)
$$

where $y^{*}$ is the predicted presence probability, $\beta_{0}$ is the intercept coefficient, $s$ is the penalized cubic regression spline function to describe the nonlinear environmental effects on the response variable, $x_{k}$ is the $k$ th explanatory variable. We used automatically selected degree of freedom to determine the smoothness of $s$ (Wood, 2006). The GAM analysis was performed using the "gam" function of the "mgcv" package in the R platform and the gamma parameter was set to 1.4 to avoid overfitting (Wood, 2006; Wood, 2014).

The GWR model is the extension of GLM by accounting for spatial location in the parameter estimates and thus allows for exploring spatially-varying species-environment relationships. The GWR model in this study can be denoted as:

$$
\ln \left(\frac{y_{i}{ }^{*}}{1-y_{i}{ }^{*}}\right)=\beta_{0}\left(u_{i}, v_{i}\right)+\sum_{k=1}^{4} \beta_{k}\left(u_{i}, v_{i}\right) x_{k}
$$

where $y_{i}{ }^{*}$ is the predicted presence probability at location $i,\left(u_{i}, v_{i}\right)$ is the coordinates of location $i, \beta_{0}$ is the intercept parameter specific to location $i, \beta_{k}$ is the regression parameter for the $k$ th environmental variables specific to location $i$. The fixed number of observations (adaptive bandwidth) nearest to the regression point are used to calibrate the local regression models in this study. The weights of observations to local parameter estimates are commonly set as decreasing with the distance to regression point and several forms of function can be used to calculate 
167

168

169

170

171

172

173

174

175

176

177

178

weights. We used the Gaussian weighting function (Eq.3) as its continuity easier for differential calculation.

$$
w_{i j}=\exp \left(-\frac{d_{i j}^{2}}{h}\right)
$$

where $d_{i j}$ is the Euclidean distance between the two sample sites $i$ and $j ; h$ is the bandwidth and has a great impact on the model results. The optimal value of $h$ was selected by minimizing the Akaike's Information Criterion (AIC). The GWR analysis was performed based on the "GWmodel" package in the R platform (Gollini et al., 2015).

The spatial variability of local regression parameter for each environmental variable from the GWR was estimated as the stationary index (SI) (Brunsdon et al., 1998). SI was calculated by dividing the interquartile range of a GWR regression coefficient by twice the s.e. of the same parameter estimate from the global logistic regression model (Windle et al., 2010). SI $>1$ indicates significant spatial non-stationarity $(p<0.05)$.

The local regression parameter estimates from the GWR for juveniles (GWR-J) and adults (GWR-A) were interpolated to continuous surfaces and then mapped to visualize spatiallyvarying environmental effects on the presence probabilities of Yellow Perch. In order to characterize the special zones of species-environment relationships, the local regression coefficient estimates from the GWR were separated into different groups using a $k$-means cluster analysis method. The number of clusters $(k)$ was set a prior to 3 and 4 for comparison with basins and MUs respectively. Furthermore, the best number of clusters was estimated based on a gap statistic (Tibshirani et al., 2001). The spatial distribution of clusters was mapped. All the maps were produced by the ArcGIS (ESRI, v. 10.2) software.

Spatially-varying species-environment relationships were accounted for by pooling the long-term (27 years) survey data to conduct the GWR analysis. However, the presence of Yellow Perch and ecological relationships are likely varying during the survey time. We plotted the GWR residuals by year in order to look for signatures of temporal effects.

\section{Model evaluation and comparison}

AIC and deviance explained (\%) were calculated to assess goodness-of-fit for each model. The model with the lower AIC and higher deviance explained would be judged to have better fitting performance. Modelling the binary data can be treated as classified algorithm and a larger area under the receiver operating characteristic (ROC) curve (AUC) value indicated the higher discrimination accuracy (Bradley, 1997). To evaluate whether a model captured the spatial patterns in the response variable, we calculated Moran's I to test for the spatial autocorrelation in model residuals. Value of Moran's I close to -1 and 1 indicates strong clustering and dispersing respectively. A permutation test for Moran's I statistic was used to test for significance of spatial autocorrelation (Bivand and Wong, 2018).

To assess the predicted accuracy of the model, the survey data were split into training and testing data randomly as a ratio of $3: 1$. The training data were used to fit the model and the testing data were used to validate the model. AUC was used to assess the discrepancy between 
205

206

207

208

209

210

211

212

213

214

215

216

217

218

219

220

221

222

223

224

225

226

227

228

229

230

231

232

233

234

235

236

237

238

239

240

241

242

243

244

the predicted and observed values. The cross-validation was repeated 100 times for calculating the mean AUC value and its 95\% confidence interval.

\section{Results}

Environmental conditions vary widely among the three basins in Lake Erie. Water temperature and depth increase and decrease from east to west respectively (Fig. 1A-1B). The waters of the east basin are clearer than those in the west and central basins (Fig. 1C). Dissolved oxygen concentration does not show marked spatial difference in the Lake Erie (Fig. 1D), primarily because of the post-turnover timing of the central basin survey. Juveniles are present at $58 \%$ of sample sites, while adults are present at $90 \%$ of sample sites. The spatial distribution map indicates that juveniles are mainly distributed in the central and west basins and the high absence is found in the east basin (Fig. 2A). Adults are present in most sample areas and high absences are found in the deep waters of the east basin and near-shore areas in the central basin (Fig. 2B).

GAM results show that water temperature, water depth, water clarity and dissolved oxygen have significant effects on the presence probability of juveniles, yet only the first three variables significantly affect the adults distribution (Table 1). The presence probability of juveniles significantly increases with water temperature and dissolved oxygen, decreases with water clarity, and first increases and then decreases with water depth (Fig. 3A-3D). The presence probability of adults shows similar change trend with that of juveniles to the variation of water temperature, water depth and dissolved oxygen (Fig. 3E-3G).

Based on the AIC criteria, GWRs with adaptive bandwidths of 64 and 241 points have the best performance for juveniles and adults, respectively. Although the bandwidth was estimated based on model fitting, it indicated the scale of similarity in environment-distribution relationships. GWRs result in marked decreases of AIC values and increases of deviance explained indicating better goodness-of-fit compared with the equivalent GAMs. GWRs also present the high prediction accuracy indicating by the higher AUC values than the equivalent GAMs. Moran's I test results show that spatial autocorrelations of model residuals from the GAMs and GWRs are not significant, implying the two types of models can capture the spatial patterns of the response variable (Table 2).

Descriptive statistics of local regression coefficient estimates from the GWRs reveal the much variations of coefficient values. SI values are all greater than 1 indicating the significantly spatial nonstationary relationships between the presence probability of Yellow Perch and environmental variables $(p<0.05$; Table 3$)$. The estimated coefficient values of water temperature, water depth, water clarity and DO for juveniles from the GWR vary between -0.40$0.28,-0.16-0.47,-0.86-0.25$ and $-0.51-0.55$, respectively (Fig.4). The significant positive associations $(p<0.05)$ between water temperature and presence of juveniles were found in most areas of the east basin and significant negative associations $(p<0.05)$ were found in the west end of west basin. Two small areas show significant positive associations $(p<0.05)$ and one small area shows significant negative associations $(p<0.05)$ between water temperature and presence of juveniles in the central basin (Fig. 4A). The presence of juveniles presents significant positive associations $(p<0.05)$ with water depth in the west basin and in the shallower waters of central 
245 and east basins and significant negative associations $(p<0.05)$ in the deeper waters of east basin 246 (Fig. 4B). Water clarity is negatively related with the presence of juveniles in most areas of Lake 247 Erie and the significant relationships $(p<0.05)$ were found in the central parts of east and west 248 basins and in the east part of central basin (Fig. 4C). Significant positive associations $(p<0.05)$ 249 between the presence of juveniles and dissolved oxygen concentrations were found in the west 250 basin and significant negative associations $(p<0.05)$ were found in some areas of central basin 251 (Fig. 4D). The estimated coefficient values of water temperature, water depth, water clarity and 252 DO for adults from the GWR vary between $-0.038-0.69,-0.15-0.33,-1.0-0.027$ and $-0.12-0.41$, 253 respectively (Fig.5). The presence of adults increases with water temperature in almost all areas and significant associations $(p<0.05)$ between them were found in the western basin (Fig. 5A). Water depth had no significant effect on the presence of adults for all the sample sites in Lake Erie (Fig. 5B). The negative associations between water clarity and presence of adults are present in almost all areas and the significant associations $(p<0.05)$ were found in the west part of Lake Erie (Fig. 5C). The associations of DO with the presence of adults are not significant for all the sample sites (Fig. 5D).

The $k$-means cluster analysis of local regression coefficient estimates from the GWRs characterized the special zones of environmental effects on the Yellow Perch distribution (Fig. 6 and 7). The $k$-means cluster analysis when $k=2$ indicates the species-environment relationships for juveniles in the nearshore areas of east basin and part areas of west and central basins are specialized as cluster 2 and the rest of Lake Erie is specialized as cluster 1 (Fig. 6A). As $k$ changed from 2 to 3, the areas of cluster 2 do not change and the areas of cluster 1 are further divided into two groups. The different species-environment relationships are found in all the three basins (Fig. 6B). As $k$ changed from 3 to 4, the areas of cluster 1 and 3 change little and the areas of cluster 2 are further divided into two groups. The ecological relationships for juveniles in each management unit are not classified as one group (Fig. 6C). The $k$-means cluster analysis of $k=2$ divides Lake Erie into distinct longitudinal zones of environmental effects on the adult distribution (Fig. 7A). The areas of cluster 1 are further cut into two parts as $k$ changed from 2 to 3. West and east basins show consistent species-environment relationships (Fig. 7B). As $k$ changed from 3 to 4, the east areas (cluster 2) are further separated into two adjacent parts and the two groups located in the west of Lake Erie change little. Consistent species-environment relationships were found in MU1 and MU4 (Fig. 7C). Based on the gap statistics, the best numbers of clusters for juveniles and adults are both two.

The GWR residuals changed significantly among years for juveniles $(p<0.05)$. The average residuals markedly lower than zero in 1998, 2001, 2003 and 2005 for juveniles indicated GWR overestimates the probabilities of juveniles in these years. The GWR residuals changed insignificantly among years for adults ( $p>0.05$; Fig. 8 ).

\section{Discussions}

Water temperature is an essential factor for the growth of juvenile Yellow Perch. Juveniles prefer to live in the warmer waters when the water temperature below the optimal range (20.0 to

$\left.23.3^{\circ} \mathrm{C}\right)$ (McCauley \& Read, 1973; Power \& Heuvel, 1999). GWR results indicated the presence

Peer) reviewing PDF | (2019:02:35025:1:1:NEW 23 May 2019) 
285

286

287

288

289

290

291

292

293

294

295

296

297

298

299

300

301

302

303

304

305

306

307

308

309

310

311

312

313

314

315

316

317

318

319

320

321

322

323

of juveniles increased with water temperature in the east basin featured with the low water temperature and this was consistent with the previous finding. By contrast, GWR results also proved that the presence of juveniles decreased with water temperature when it over the optimal range (20.0-23.3 $\left.{ }^{\circ} \mathrm{C}\right)$ for juveniles in the west basin (McCauley \& Read, 1973). GAM pooled all the survey data and yielded a mean trend in the association of the presence of juveniles with water temperature, which masked the interaction between water temperature and juvenile distribution at finer scales.

Water depth and water clarity in Lake Erie generally increase from west to east. According to the GAM results, the presence of Yellow Perch first increased and then decreased with water depths greater than $20 \mathrm{~m}$. This result projected to space by GWR was presented as the increment of the presence of Yellow Perch with water depth in the shallower waters and the decrement with water depth in the deeper waters. Juveniles prefer to inhabit the shallower, more turbid waters for avoiding pelagic, visual predators (Manning et al., 2013). This finding was verified by the GAM results of the significant decrease of Yellow Perch presence with increasing water clarity. However, clearer waters are good for the growth of juveniles by improving the visual field and increasing the foraging success rates (Manning et al., 2013), possibly explaining why the presence of juveniles increased with the water clarity in parts of Lake Erie based on the GWR results.

Dissolved oxygen concentrations below threshold or fluctuating diurnally are not conducive to the growth of juveniles (Bejda et al., 1992). Hypolimnetic hypoxia $\left(<2 \mathrm{mg} \mathrm{O}_{2} / \mathrm{L}^{-1}\right)$ can cause Yellow Perch to escape from the hypoxic habitats to the more oxygenated areas and alter the fish distribution (Roberts et al., 2012). Over $99 \%$ of the sample sites have dissolved oxygen concentrations above the hypoxic threshold and this is probably the reason to cause the insignificant effect of dissolved oxygen on the presence of adults. Liu et al. (2018) also found dissolved oxygen did not affect adult Yellow Perch distribution significantly. GAM results indicated the general trend of the presence of juveniles significantly increasing with dissolved oxygen concentration. This finding may not be appropriate for applying at the local scale. Juveniles prefer to live in the more oxygenated areas for optimizing the growth in the shallower, warmer waters. However, as dissolved oxygen concentration over a certain value, it is not an important factor to affect juvenile's distribution. Liu et al. (2018) found the significant interactive effect of dissolved oxygen with water depth on the distribution of juvenile Yellow Perch in Lake Erie. GWR results proved that the effect of dissolved oxygen on juvenile's distribution depending on water depth and are consistent with the earlier findings.

The presence probability of species can be affected by catchability in addition to habitat variables. We assumed the constant catchability over space and time and this may cause bias to the model results. For example, as a visual forager, adult Yellow Perch may prefer to live in the clearer waters for optimal predation, yet they may detect and avoid gillnets in these waters. The long-term ( $>20$ years) dataset, stratified random sampling design and randomly ordered multifilament mesh sizes of the PIS are expected to reduce any such bias. 
324

325

326

327

328

329

330

331

332

333

334

335

336

337

338

339

340

341

342

343

344

345

346

347

348

349

350

351

352

353

354

355

356

357

358

359

360

361

362

363

364

Our cluster analysis characterized special zones of species-environment relationships. Liu et al. (2017) achieved similar results in analyzing the relationships between walleye distribution and environmental factors in Lake Erie. In order to detect whether a consistent speciesenvironment relationship exists in each basin, we divided the local regression coefficients of GWR into three groups based on the $k$-means cluster analysis. Different ecological relationships were found for juveniles in all the three basins. The sensitivity to spatial environmental variation for juveniles is probably the reason for the different relationships in all the three basins. Consistent ecological relationships were found in the west and east basins for adults. The distinctive environmental attributes with warmer, shallower, more turbid and colder, deeper, clearer waters in the west and east basins respectively may be the reasons to shape the special zones of ecological relationships for adults. Lake Erie was partitioned into four MUs and total allowable catch (TAC) of Yellow Perch was allocated based on MUs each year (YTPG, 2015). The MU boundaries were identified with full consideration of socioeconomic concerns (e.g., at least one major port exists within each MU) and political boundaries (e.g., counties in Ontario) (Kocovsky \& Knight, 2012). Hence, MUs are convenient for landing and reporting of harvest and may lack of ecological significance to some degree. When comparing the $k$-means cluster analysis $(k=4)$ results for adults with MUs, consistent species-environment relationships were found in MU1 and MU4 and two different kinds of species-environment relationships were found in MU2 and MU3. This implied the variation of species-environment relationships at a scale finer than the management unit. Henderson and Nepszy (1989) reported central basin Yellow Perch were larger at age than western basin Yellow Perch. They also noted the different mortality and growth rates. Sepulveda-Villet and Stepien (2011) and Kocovsky \& Knight (2012) provided strong evidence based on genetic and morphological analysis respectively that Yellow Perch exist as discrete stocks in Lake Erie and that stocks exist at scales finer than the current MUs. Our analysis further facilitates verification of stocks for Yellow Perch from the perspective of species-environment interactions. Management of Yellow Perch should benefit through considering such kind of species-environment differentiations. Comprehensive analysis with additional explanatory variable included in the GWR coupled with genetic and morphological research can provide supports for identification of unique stocks and refinement of the current MU structure in consideration of ecological relevance for sustainable management of Yellow Perch.

Density data (catch weight) were available for Yellow Perch at each sample site. Adults were present at $90 \%$ of sample sites and the absences were mainly distributed in the east basin. Analysis based on the presence/absence data of adults may mask the species-environment relationships at finer scales because of the evident low proportion of absence data. The difference of density data for adults was significant among sample sites $(p<0.05)$. Further analysis based on density is suggested in the future.

The predominant advantage of GWR is the ability to capture the spatially-varying ecological relationships. Furthermore, GWR can be used as an identifier to determine at which scale the species-environment relationships become stationary (Windle et al., 2010). Generalized additive mixed model (GAMM) is also able to allow the spatial variation to be described using a

Peer] reviewing PDF | (2019:02:35025:1:1:NEW 23 May 2019) 
365

366

367

368

369

370

371

372

373

374

375

376

377

378

379

380

381

382

383

384

385

386

387

388

389

390

391

392

393

394

395

396

397

398

399

400

401

402

403

404

complex spatial field, such as a Gaussian random field. Due to the complexity of GAMM, it has seldom been used to explore spatial nonstationary species-environment relationships. For comparison with GWRs, we also used GAMMs to estimate spatially-varying ecological relationships. The performance of GAMMs was improved over that of GAMs as indicated by the lower AIC values, but GWRs were still superior to GAMMs. Liu et al. (2017) also found the superiority of GWR over GAMM when spatially nonstationary species-environment relationships were present. The main advantages of GWR over GAMM are that we can map the local relationships from the GWR and identify the distinct zones of species-environment relationships.

The presence and response of Yellow perch to environmental variations may vary among years. The long-term (27 years) survey data were pooled and the temporal effects were not accounted for when conducting GWR analysis in this study. This resulted in lower goodness-offit and higher model residuals in several years. For example, GWR provides inferior performance in 1998, 2001, 2003 and 2005 because the presences of juveniles in these years were markedly lower than the mean presence calculated based on the data from all years. Multilevel categorical variable (e.g. year in this study) was not recommended as an explanatory variable in the GWR analysis because of the strong risk to cause collinearity in the local regression coefficients (Wheeler \& Tiefelsdorf, 2005). Geographically and temporally weighted regression (GTWR) was developed by incorporating temporal effects into the GWR to deal with both spatial and temporal nonstationarity simultaneously (Fotheringham et al., 2015). Future research in this area should focus on estimating spatial and temporal nonstationary ecological relationships for Yellow Perch in Lake Erie.

Although the GWR was shown to be superior to the global regression models, it should be used with caution. Due to local regression coefficients estimated based on the neighborhood observations, GWR cannot be used to predict species distribution outside the study area. Spatial coordinates are the only information required by GWR to estimate local regression coefficients at unobserved locations. Thus, GWR cannot be used to predict future distribution of species. The possible collinearity in local regression coefficients may limit the interpretation of speciesenvironment relationships (Wheeler \& Tiefelsdorf, 2005). The prediction accuracy of GWR is sensitive to data quantity. Thus, conducting the GWR separately for each year in this study may not be sufficient to get ecologically meaningful results. The large data quantity required to estimate local regression coefficients also limits the application of GWR.

\section{Conclusions}

Developing a global regression model by pooling all the survey data in the large region may mask the local variability in the processes being studied although such an approach is more convenient to conduct. We applied the GWR to test the assumption of spatial stationarity in estimating the relationships between Yellow Perch distribution and environmental variables in Lake Erie. Our analysis demonstrated that environmental effects on the Yellow Perch distribution varied significantly among locations, and verified the existence of discrete speciesenvironment relationships for Yellow Perch in Lake Erie. Our analysis further facilitates 
405

406

407

408

409

410

411

412

413

414

415

416

417

418

419

420

421

422

423

424

425

426

427

428

429

430

431

432

433

434

435

436

437

438

439

verification of discrete Yellow Perch stocks from the perspective of species-environment interactions. Management of Yellow Perch should benefit through considering such speciesenvironment spatial differentiations. Despite its limitations, GWR is recommended as a complementary tool for global regression models in exploring spatially-varying ecological relationships. We suggest expanded research is needed to explore spatio-temporal nonstationary species-environment relationships for Yellow Perch in Lake Erie using a GTWR model.

\section{Acknowledgements}

We thank the Ontario Commercial Fisheries' Association, Lake Erie Management Unit of the Ontario Ministry of Natural Resources and Forestry and the Lake Erie Committee of the Great Lakes Fishery Commission for providing the data to us. We also acknowledge support from the Department of Fisheries, Ocean University of China.

\section{References}

\section{Arend KK, Beletsky D, Depinto JV, Ludsin SA, Roberts JJ, Rucinski DK, Scavia D,} Schwab DJ, HöÖK TO. 2011. Seasonal and interannual effects of hypoxia on fish habitat quality in central Lake Erie. Freshwater Biology 56: 366-383.

DOI 10.1111/j.1365-2427.2010.02504.x

Canepa A, Fuentes V, Bosch-Belmar M, Acevedo M, Toledo-Guedes K, Ortiz A, Durá E, Bordehore C, Gili JM. 2017. Environmental factors influencing the spatiotemporal distribution of Carybdea marsupialis (Lineo, 1978, Cubozoa) in South-Western Mediterranean coasts. PLoS ONE 12: e0181611. DOI 10.1371/journal.pone.0181611.

Bacheler NM, Paoli TJ Schacht GM. 2011. Controls on abundance and distribution of Yellow Perch: predator, water quality, and density-dependent effects. Transactions of the American Fisheries Society 140: 989-1000

DOI 10.1080/00028487.2011.603979

Barbeaux SJ, Holloweb AB. 2017. Ontogeny matters: Climate variability and effects on fish distribution in the eastern Bering Sea. Fisheries Oceanography 27:1-15. DOI 10.1111/fog. 1222 .

Bejda AJ, Phelan BA, Studholme AL. 1992. The effect of dissolved oxygen on the growth of young-of-the-year winter flounder, Pseudopleuronectes americanus. Environmental Biology of Fishes 34: 321. DOI: 10.1007/BF00004780.

Berger AM, Jones ML, Zhao Y. 2012. Improving fishery independent indices of abundance for a migratory walleye population. Journal of Great Lakes Research 38: 755-765. DOI 10.1016/j.jglr.2012.09.012.

Bi R, Jiao Y, Zhou C, Hallerman E. 2019. A Bayesian spatiotemporal approach to inform management unit appropriateness. Canadian Journal of Fisheries and Aquatic Science 76: 
217-237. DOI 10.1139/cjfas-2017-0526.

Bivand RS, Wong DWS. 2018. Comparing implementations of global and local indicators of spatial association. Test 27: 716-748.

DOI 10.1007/s11749-018-0599-X

Bradley A. 1997. The use of the area under the ROC curve in the evaluation of machine learning algorithms. Pattern Recognition 30: 1145-1159.

DOI 10.1016/S0031-3203(96)00142-2.

Cowan ER, Paine J. 1997. The introduction of individual transferable quotas to the Lake Erie fishery. Department of Fisheries and Oceans, Ontario, Canada.

Fotheringham AS, Charlton M, Brunsdon C. 1997. Two techniques for exploring nonstationarity in geographical data. Geographical System 4: 59-82.

Fotheringham AS, Charlton ME, Brunsdon C. 1998. Geographically weighted regression: a natural evolution of the expansion method for spatial data analysis. Environment and Planning A 30: 1905-1927. DOI 10.1068/a301905.

Fotheringham AS, Brunsdon C, Charlton M. 2002. Geographically Weighted Regression: the Analysis of Spatially Varying Relationships. John Wiley \& Sons, Chichester, England.

Fotheringham AS, Crespo R, Yao J. 2015. Geographical and temporal weighted regression (GTWR). Geographical Analysis 47: 431-452.
DOI 10.1111/gean.12071.

Gollini I, Lu BB, Charlton M, Brunsdon C, Harris P. 2015. GWmodel: An R Package for Exploring Spatial Heterogeneity Using Geographically Weighted Models. Journal of Statistical Software 63: 1-50.

Grieve BD, Hare JA, Saba VS. 2017. Projecting the effects of climate change on Calanus finmarchicus distribution within the U.S. Northeast Continental Shelf. Scientific Reports 7:1-12. DOI 10.1038/s41598-017-06524-1.

Grüss A, Thorson JT, Babcock EA, Tarnecki JH. 2017. Producing distribution maps for informing ecosystem-based fisheries management using a comprehensive survey database and spatio-temporal models. ICES Journal of Marine Science 75:1-20 DOI 10.1093/icesjms/fsx120.

Hartman WL. 1972. Lake Erie: effects of exploitation, environmental changes, and new species on the fishery resources. Journal of the Fisheries Research Board of Canada 29:931-936.

Henderson BA, Nepszy SJ. 1989. Yellow perch (Perca flavescens) growth and mortality rates in Lake St. Clair and the three basins of Lake Erie, 1963-86. Journal of Great Lakes Research 15: 317-326. DOI 10.1016/S0380-1330(89)71485-4.

Hemami MR, Ahmadi M, Sadegh-Saba M, Moosavi MH. 2018. Population estimate and 
475

476

477

478

479

480

481

482

483

484

485

486

487

488

489

490

491

492

493

494

495

496

497

498

499

500

501

502

503

504

505

506

507

508

509

distribution pattern of Indian Ocean humpback dolphin (Sousa plumbea) in an industrialised bay, northwestern Persian Gulf. Ecological Indicators 89:631-638. DOI 10.1016/j.ecolind.2018.02.031.

Kocovsky PM, Knight CT. 2012. Morphological evidence of discrete stocks of yellow perch in Lake Erie. Journal of Great Lakes Research 38:534-539.

DOI 10.1016/j.jglr.2012.04.006

Liu C, Wan R, Jiao Y, Kevin B. R. 2017. Exploring non-stationary and scale-dependent relationships between walleye (Sander vitreus) distribution and habitat variables in Lake Erie. Marine \& Freshwater Research 68:270-281. DOI 10.1071/MF15374. DOI 10.1007/s10750-017-3440-8.

Li B, Cao J, Guan L, Mazur M, Chen Y, Wahle, RA. 2018. Estimating spatial non-stationary environmental effects on the distribution of species: a case study from American lobster in the Gulf of Maine. ICES Journal of Marine Science 75:1473-1482. DOI 10.1093/icesjms/fsy024.

Li Y, Jiao Y, Browder JA. 2016a. Modeling spatially-varying ecological relationships using geographically weighted generalized linear model: A simulation study based on longline seabird bycatch. Fisheries Research 181:14-24. DOI 10.1016/j.fishres.2016.03.024.

Li Y, Jiao Y, Browder JA. 2016b. Assessment of seabird bycatch in the U.S. Atlantic pelagic longline fishery, with an extra exploration on modeling spatial variation. ICES Journal of Marine Science 73:2687-2694. DOI 10.1093/icesjms/fsw088.

Liu CD, Wan R, Jiao Y, Reid KB. 2017. Exploring non-stationary and scale-dependent relationships between walleye (Sander vitreus) distribution and habitat variables in Lake Erie. Marine and Freshwater Research 68:270-281. DOI 10.1071/MF15374

Liu CD, Jiao Y, Reid KB, Tang YL, Ma SY. 2018. Habitat supply for Yellow Perch (Actinopterygii, Percidae) varies with space, time, and life stage in Lake Erie. Hydrobiologia 808:371-386. DOI 10.1007/s10750-017-3440-8.

Manning NF, Mayer CM, Bossenbroek JM, Tyson JT. 2013. Effects of water clarity on the length and abundance of age-0 Yellow Perch in the Western Basin of Lake Erie. Journal of Great Lakes Research 39: 295-302.

DOI 10.1016/j.jglr.2013.03.010.

McCauley RW, Read LAA. 1973. Temperature selection by juvenile and adult yellow perch (Perca flavescens) acclimated to $24^{\circ} \mathrm{C}$. Journal of the Fisheries Research Board of Canada 30:1253-1255.

Muška M, Tušer M, Frouzová J, Mrkvička T, Ricard D, Seda J, Morelli F, Kubečka J. 2018. Real-time distribution of pelagic fish: combining hydroacoustics, gis and spatial 
510

modelling at a fine spatial scale. Scientific Reports 8:5381.

Pandit SN, Zhao YM, Ciborowski JJH, Gorman AM, Knight CT. 2013. Suitable habitat model for walleye (Sander vitreus) in Lake Erie: implications for inter-jurisdictional harvest quota allocations. Journal of Great Lakes Research 39: 591-601. DOI 10.1016/j.jglr.2013.09.011.

Peterson LK. 2014. An investigation of Lake Eire Yellow Perch stock assessment assumptions. Master of Science Thesis, Michigan State University.

Power M, Heuvel MR. 1999. Age-0 Yellow Perch growth and its relationship to temperature. Transactions of the American Fisheries Society 128: 687-700. DOI 10.1577/1548-8659(1999)128<0687:aypgai $>2.0$. co;2

\section{Roberts JJ, Grecay PA, Ludsin SA, Pothoven SA, Vanderploeg HA, Höök TO. 2012.} Evidence of hypoxic foraging forays by yellow perch (Perca flavescens) and potential consequences for prey consumption. Freshwater Biology 57:922-937. DOI 10.1111/j.13652427.2012.02753.x

Sadorus LL, Mantua NJ, Essington T, Hickey B, Hare S. 2014. Distribution patterns of Pacific halibut (Hippoglossus stenolepis) in relation to environmental variables along the continental shelf waters of the US West Coast and southern British Columbia. Fisheries Oceanography 23:225-241. DOI 10.1111/fog.12057.

Sepulveda-Villet OJ, Stepien CA. 2011. Fine-scale population genetic structure of the yellow perch Perca flavescens in Lake Erie. Canadian Journal of Fisheries and Aquatic Sciences 68: 1435-1453. DOI 10.1139/f2011-077.

Tibshirani R, Walther G, Hastie T. 2001. Estimating the number of data clusters via the gap statistic. Journal of the Royal Statistical Society. Series B. Methodological 63: 411-423. DOI 10.1111/1467-9868.00293.

Tseng CT, Su NJ, Sun CL, Punt AE, Yeh SZ, Liu DC, Su WC. 2013. Spatial and temporal variability of the Pacific saury (Cololabis saira) distribution in the northwestern Pacific Ocean. ICES Journal of Marine Science 70: 991-999. DOI:10.1093/icesjms/fss205.

Wheeler D, Tiefelsdorf M. 2005. Multicollinearity and correlation among local regression coefficients in geographically weighted regression. Journal of Geographical Systems 7:161-187. DOI 10.1007/S10109-005-0155-6.

Windle MJ, Rose GA, Devillers R, Fortin MJ. 2010. Exploring spatial non-stationarity of fisheries survey data using geographically weighted regression (GWR): an example from the Northwest Atlantic. ICES Journal of Marine Science 67:145154. DOI 10.1093/ICESJMS/FSP224. 
545 Windle MJ, Rose GA, Devillers R, Fortin MJ. 2012. Spatiotemporal variations in invertebrate-

546

547

548

549

550

551

552

553

554

555

556

557

558

559

560

561

562

563

564 cod-environment relationships on the Newfoundland-Labrador Shelf, 1995-2009. Marine Ecology Progress Series 469:263-278.

DOI 10.3354/MEPS10026

Wood S. 2006. Generalized Additive Models: an Introduction with R. CRC Press: Boca Raton, FL.

Wood S. 2014. mgcv: mixed GAM computation vehicle with GCV/AIC/REML smoothness estimation. R package ver. 1.8-4. Available at http://CRAN.R-project.org/package=mgcv.

YPTG (Yellow Perch Task Group). 1983. Report of the Lake Erie Yellow Perch Task Group. Wheatley, Ontario.

YPTG (Yellow Perch Task Group). 2015. Report of the Lake Erie Yellow Perch Task Group. Wheatley, Ontario.

Yu H, Jiao Y, Winter A. 2011. Catch-Rate standardization for Yellow Perch in Lake Erie: a comparison of the spatial generalized linear model and the generalized additive model. Transactions of the American Fisheries Society 140:905-918. DOI 10.1080/00028487.2011.599258.

Zuur AF, Ieno EN, EIphick CS. 2010. A protocol for data exploration to avoid common statistical problems. Methods in Ecology and Evolution 1: 3-14.

DOI 10.1111/j.2041-210X.2009.00001.x. 


\section{Table $\mathbf{1}$ (on next page)}

Test statistics and significance of the four environmental variables used in the generalized additive models (GAMs) for juveniles (GAM-J) and adults (GAM-A).

A variable is significant at $p<0.05$ in the GAM. J denotes juveniles, A denotes adults, DO denotes dissolved oxygen. 
1

2

3

\begin{tabular}{ccccc}
\hline Variables & \multicolumn{2}{c}{ GAM-J } & \multicolumn{2}{c}{ GAM-A } \\
\hline$\lambda^{2}$ & $p$-value & $\lambda^{2}$ & $p$-value \\
Temperature & 82.95 & $<0.001$ & 48.20 & $<0.001$ \\
Depth & 87.25 & $<0.001$ & 81.73 & $<0.001$ \\
Transparency & 28.77 & $<0.001$ & 46.93 & $<0.001$ \\
DO & 8.28 & 0.008 & 0.00 & 0.35 \\
\hline
\end{tabular}




\section{Table 2 (on next page)}

Summary of optimal bandwidths and model performances for generalized additive models (GAMs) and geographically weighted regression (GWR) models.

The unit of bandwidth is the number of points. J denotes juveniles, A denotes adults. AIC is Akaike's information criterion. AUC is area under the receiver operating characteristic (ROC) curve. $C V \_A U C \pm S D$ is the mean $A U C \pm$ standard deviance calculated based the 100 repeated cross-validations. Moran test is the $p$-values of testing for the significance of residual spatial autocorrelations. 
1

\begin{tabular}{lllllll}
\hline Model & Bandwidth & AIC & Deviance (\%) & AUC & CV_AUC \pm SD $^{\text {A }}$ & $\begin{array}{l}\text { Moran test } \\
p \text {-value }\end{array}$ \\
\hline GAM-J & - & 2955.6 & 14.3 & 0.73 & $0.72 \pm 0.02$ & 0.18 \\
GAM-A & - & 1018.8 & 36.2 & 0.88 & $0.74 \pm 0.02$ & 0.51 \\
GWR-J & 64 & 2809.9 & 23.2 & 0.80 & $0.81 \pm 0.01$ & 0.96 \\
GWR-A & 241 & 982.3 & 41.5 & 0.91 & $0.90 \pm 0.02$ & 0.86 \\
\hline
\end{tabular}

2

3

4

5 


\section{Table 3 (on next page)}

Summary statistics of the logistic GWR local parameter estimates and spatial stationarity index (SI).

SI was calculated by dividing the interquartile range of a GWR regression coefficient by twice the s.e. of the same parameter estimate from the global logistic regression model. SI>1 indicates significant spatial non-stationarity $(p<0.05)$. J denotes juveniles, A denotes adults, DO denotes dissolved oxygen. 
1

\begin{tabular}{cccccccc}
\hline Model & Variable & Minimum & $\begin{array}{c}\text { Lower } \\
\text { quartile }\end{array}$ & Median & $\begin{array}{c}\text { Upper } \\
\text { quartile }\end{array}$ & Maximum & SI \\
\hline \multirow{5}{*}{ GWR-J } & Intercept & -9.37 & -2.47 & -0.27 & 1.40 & 6.09 & 4.68 \\
& Temperature & -0.40 & -0.06 & 0.04 & 0.10 & 0.28 & 4.86 \\
& Depth & -0.16 & 0.00 & 0.06 & 0.08 & 0.12 & 8.23 \\
& Transparency & -0.86 & -0.23 & -0.09 & 0.05 & 0.25 & 5.67 \\
& DO & -0.51 & -0.11 & -0.02 & 0.12 & 0.55 & 5.59 \\
\hline \multirow{2}{*}{ GWR-A } & Intercept & -10.34 & -4.57 & -0.70 & 3.64 & 5.64 & 5.76 \\
& Temperature & -0.04 & 0.09 & 0.14 & 0.40 & 0.69 & 3.70 \\
& Depth & -0.15 & -0.08 & 0.06 & 0.18 & 0.33 & 11.01 \\
& Transparency & -1.01 & -0.63 & -0.36 & -0.26 & 0.03 & 5.73 \\
& DO & -0.12 & -0.07 & 0.01 & 0.22 & 0.41 & 4.13 \\
\hline
\end{tabular}

2

3

4 
Figure 1

Spatial distributions of the measured values for environmental variables based on the partnership index survey (PIS) in the Canadian side of Lake Erie from 1989 to 2015.

(A) Water temperature. (B) Water depth. (C) Water transparency. (D) Dissolved oxygen. The bold black lines in Lake Erie are the separate lines among the three basins.
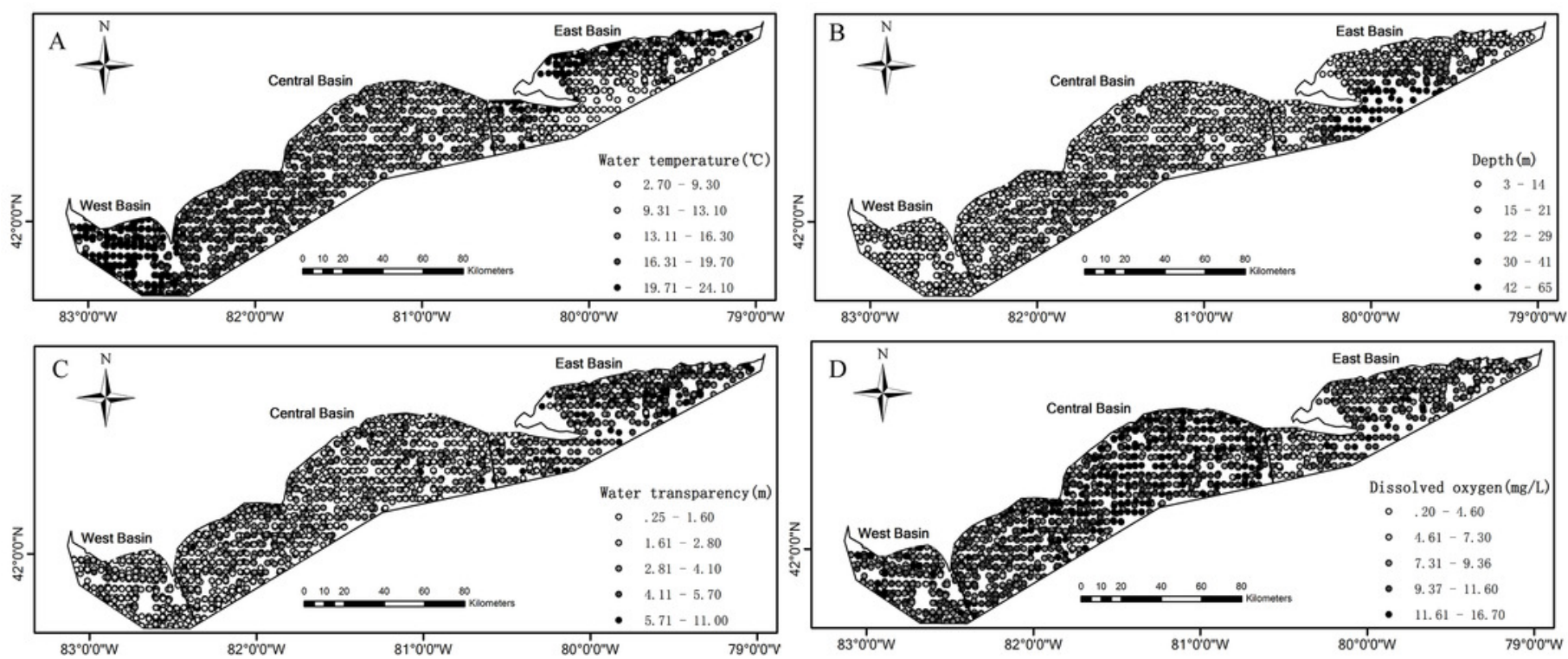
Figure 2

Spatial distributions of absence $(x)$ and presence $(O)$ for $(A)$ juvenile and $(B)$ adult Yellow Perch in the Canadian side of Lake Erie based on the partnership index survey (PIS) data.
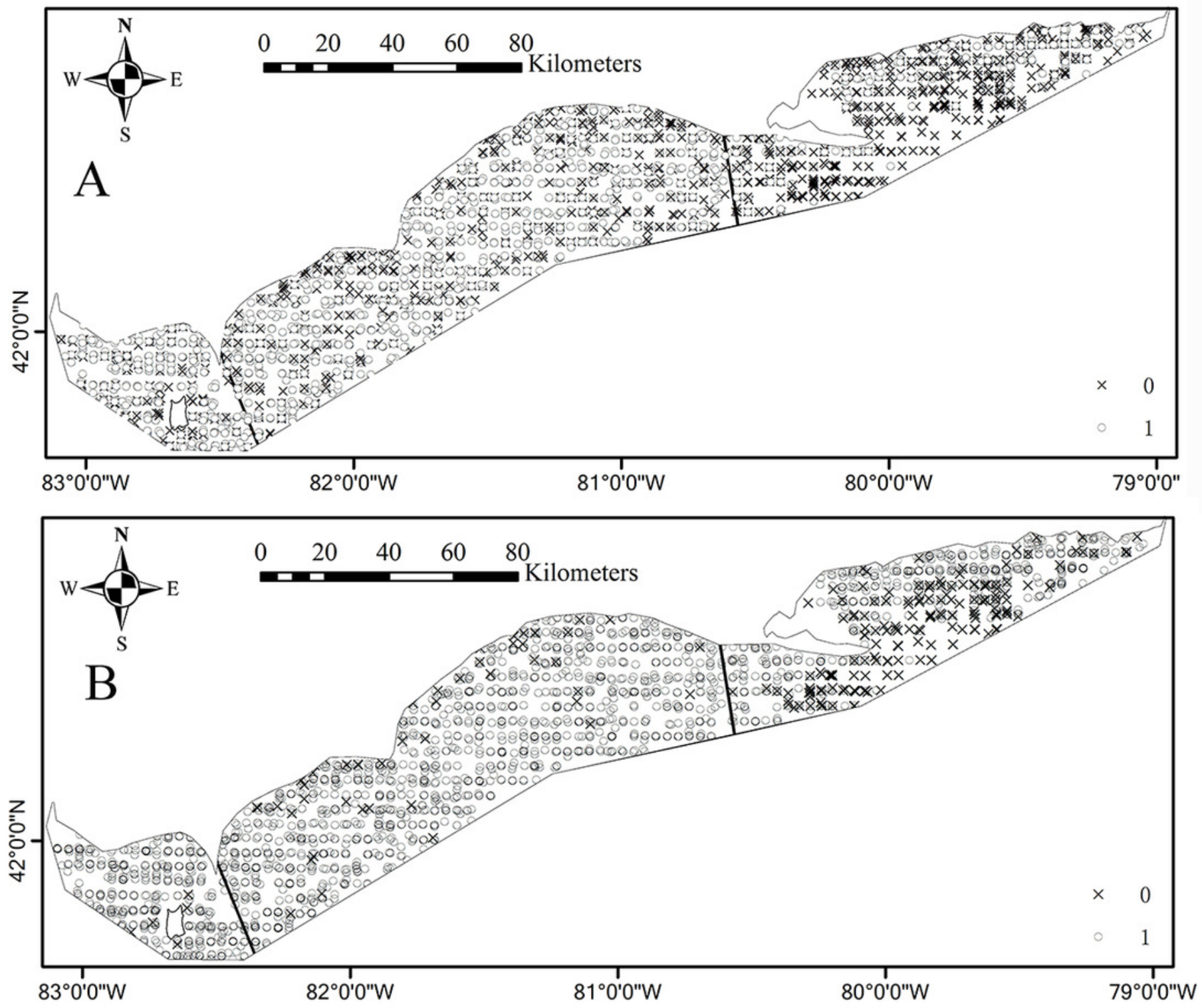


\section{Figure 3}

Environmental effects on the presence probabilities of juveniles and adults based on the generalized additive models (GAMs).

(A-D) Water temperature, water depth, water clarity and dissolved oxygen on the presence probabilities of juveniles. (E-G) Water temperature, water depth and water clarity on the presence probabilities of adults. Tick marks on the $\mathrm{x}$-axis are the observed values for each environment variable; $\mathrm{s}(\mathrm{x})$ is the cubic spline function indicating the magnitude and direction of each environment variable on the presence probabilities of juveniles and adults; and shaded areas indicate $95 \%$ confidence bounds. The relationship between dissolved oxygen concentration and presence probability of adult was not plotted because it was not significant $(p=0.35)$.
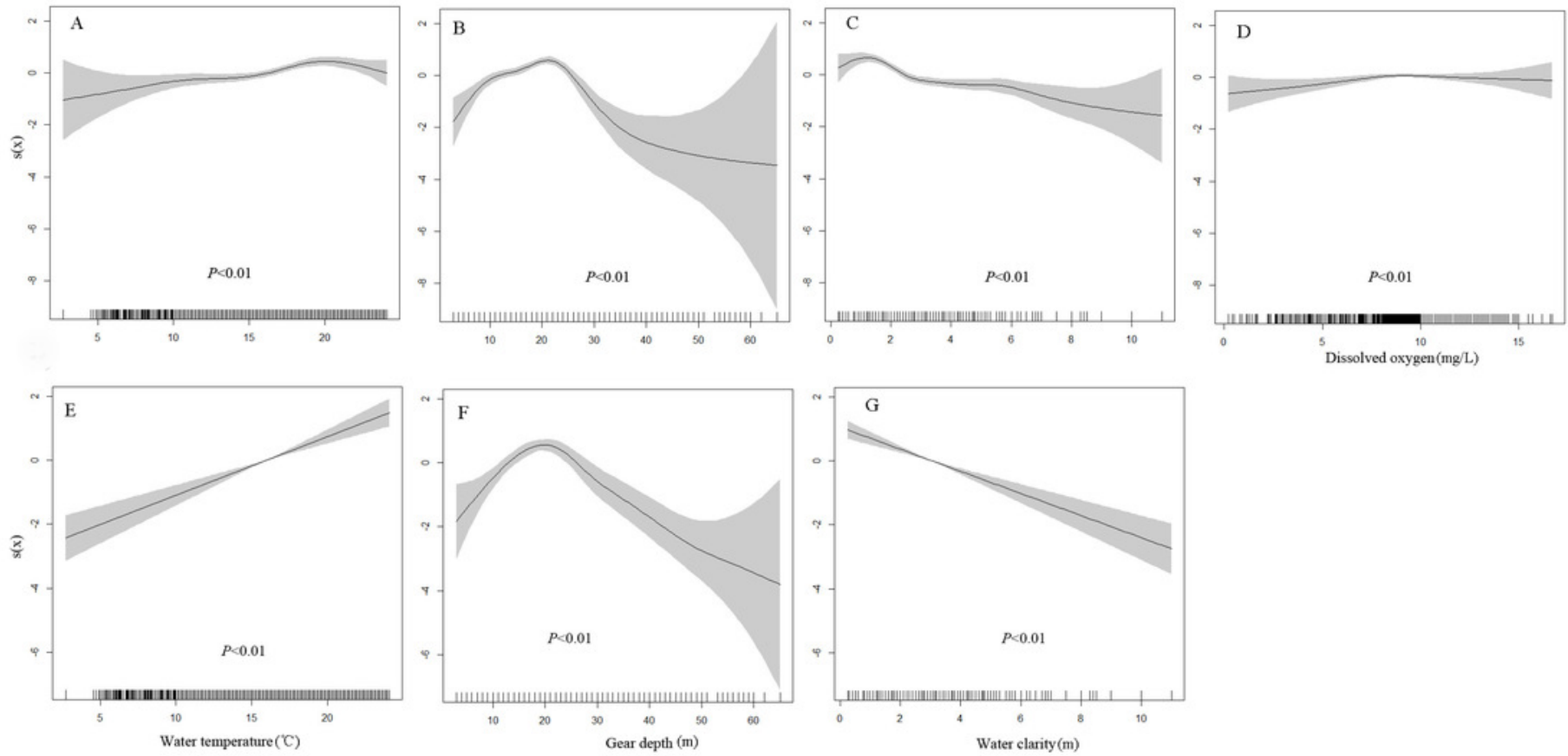
Figure 4

The interpolated continuous surfaces of the GWR local regression coefficient estimates for juveniles for (A) water temperature, (B) water depth, (C) water transparency, and (D) dissolved oxygen.

The black circles denote that the environment effect was significant $(p<0.05)$ at these sample sites.
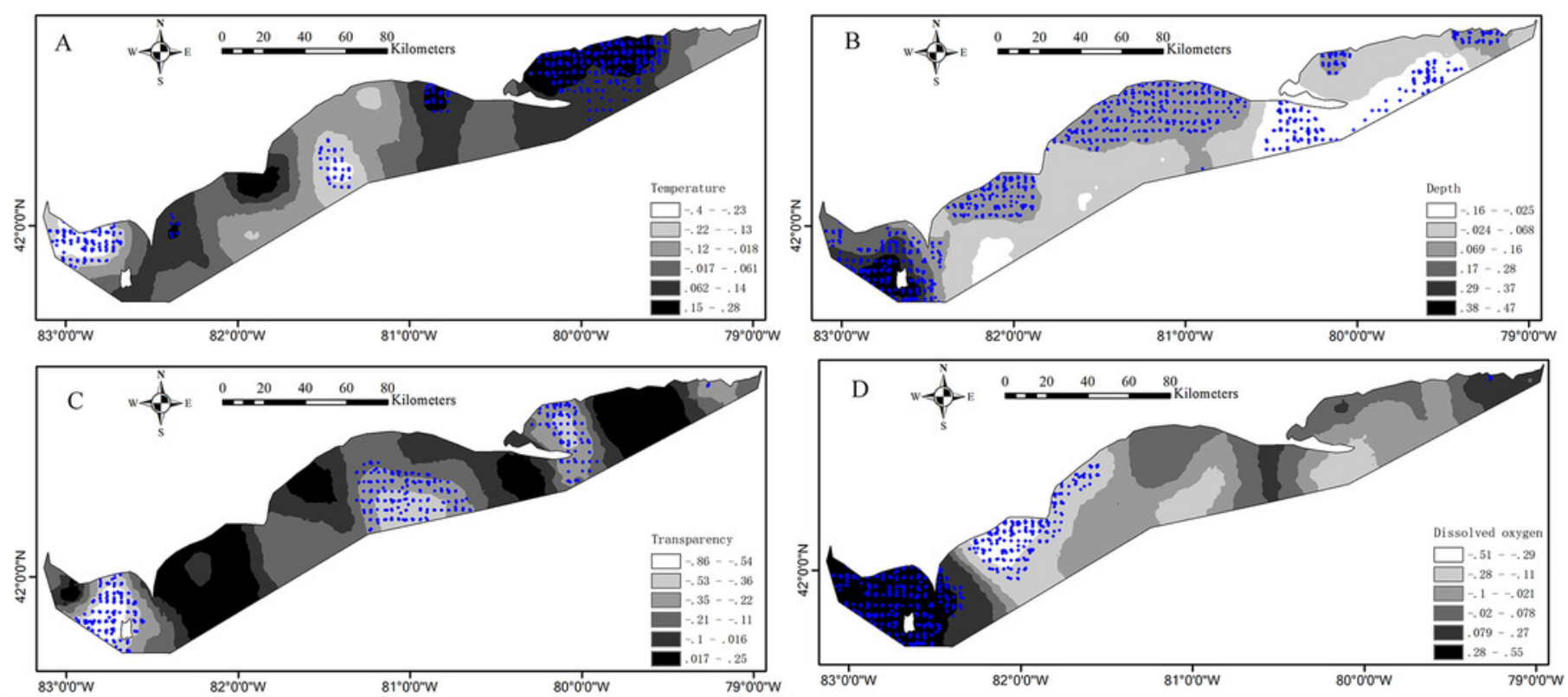


\section{Figure 5}

The interpolated continuous surfaces of the GWR local regression coefficient estimates for adults for (A) water temperature, $(B)$ water depth, $(C)$ water transparency, and (D) dissolved oxygen.

The black circles denote that the environment effect was significant $(p<0.05)$ at these sample sites.
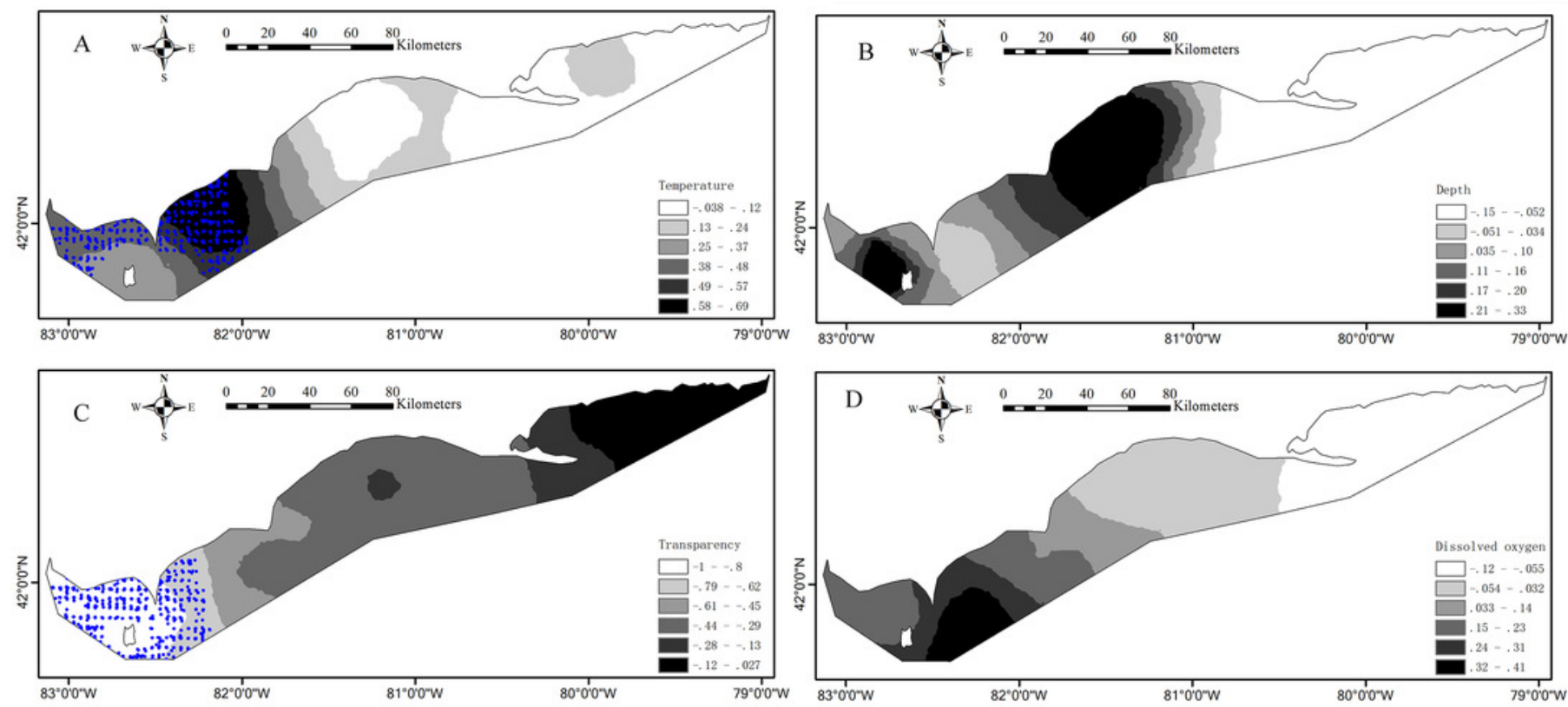
Figure 6

Mapped results of $k$-means cluster analyses to the local coefficient estimates from the logistic GWR for juveniles, for three clusters, (A) $k=2$, (B) $k=3$, (C) $k=4$.

The bold black lines in (B) and (C) are the separate lines among basins and management units, respectively.
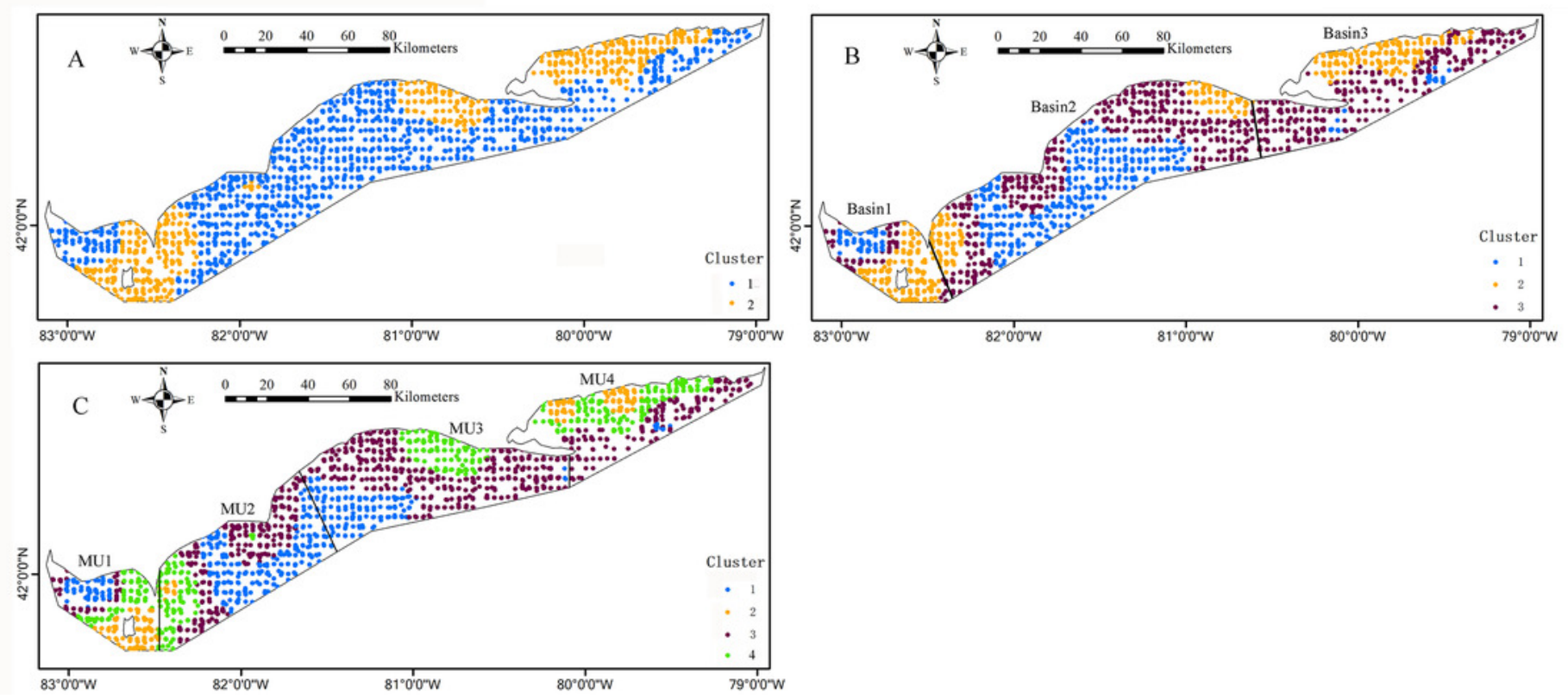
Figure 7

Mapped results of $k$-means cluster analyses to the local coefficient estimates from the logistic GWR for adults, for three clusters, (A) $k=2$, (B) $k=3$, (C) $k=4$.

The bold black lines in (B) and (C) are the separate lines among basins and management units, respectively.
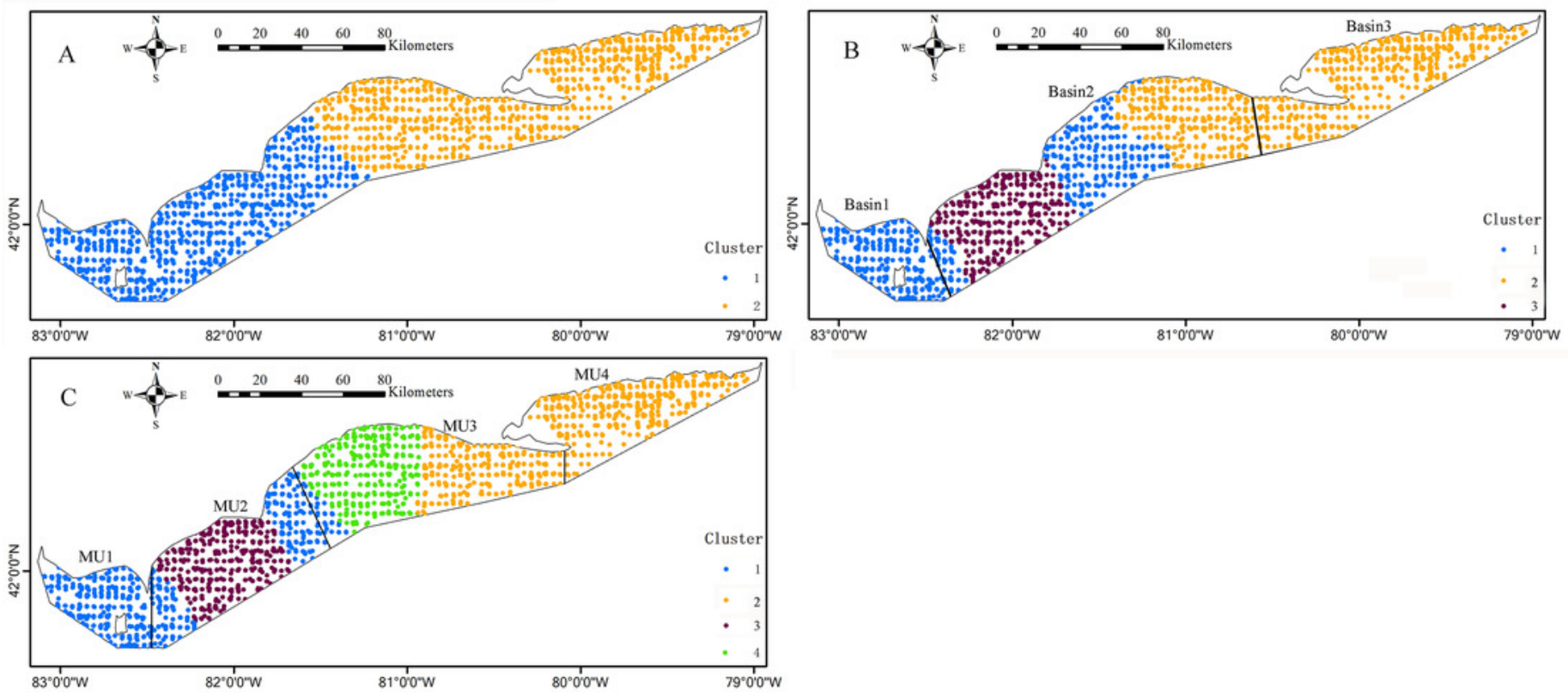


\section{Figure 8}

Mean and standard deviation (SD) values of GWR residuals against year for juveniles and adults.

The filled rectangles and diamonds denote the mean residuals in each year for juveniles and adults respectively and the vertical lines denote SDs.

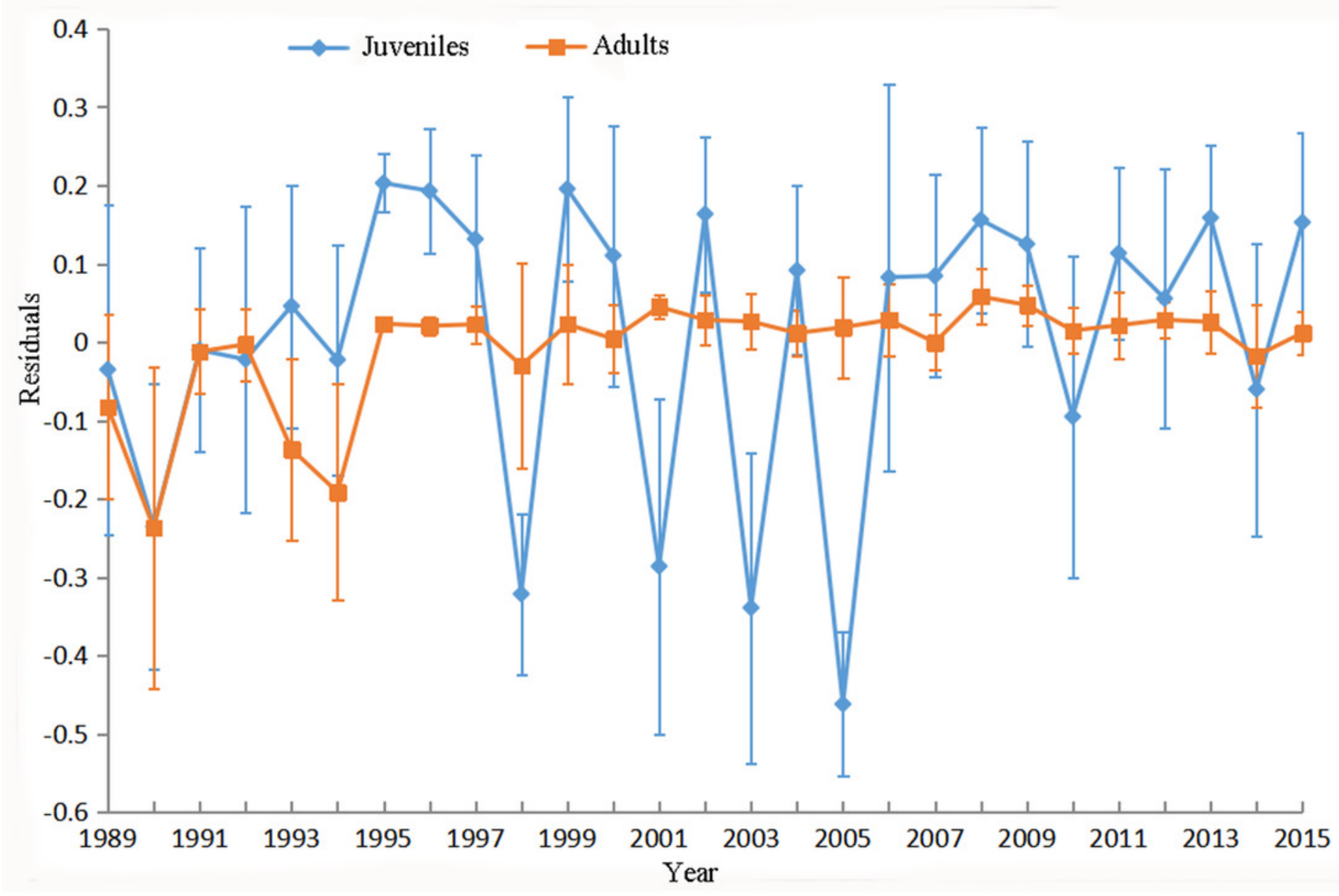

